\title{
Experiential Learning in Circles of Safety: Reflections on Walls to Bridges and Dewey's Theory of Experience
}

\author{
Judith Harris ${ }^{1}$
}

\begin{abstract}
This paper discusses a Winnipeg-based community-university partnership structured as a set of interlinked "Circles of Safety" to support criminalized women while incarcerated and after their release. The four Circles include university, community, social co-operatives, and corrections; these circles contain the action research activities we are undertaking to provide greater safety for women transitioning from prison into the community. The motivation for our prison education program, which draws on the American Inside-Out Program and the newer Canadian Walls to Bridges Program, comes from these four directions and is energized by a belief in the human right to education. This paper argues that the success of both American and Canadian programs is explained by an approach to prison education that is complementary to John Dewey's principles of educative experience, specifically principles based on continuity and interaction. Adapting and extending Dewey, the Circles of Safety model described in this paper maintains the value of experiential learning, which is defined as learning in situations that begin with the experience that the learners already have and subject matter that is within the scope of their ordinary life-experience, leading to their formation of purpose.
\end{abstract}

KEYWords community-based learning, prison-based education, experiential education, circle pedagogy, criminal justice system

Elder Marion Gracey believed that creating a safe community was more important than targeting poverty for marginalized Indigenous people in the city (B. Cyr, personal communication, February 16, 2013). Safety is the theme of a Winnipeg-based community-university partnership that is structured as a set of interlinked "Circles of Safety" to support criminalized women while incarcerated and after their release (see Figure 1). Through this project, which has focused on community-engaged education and the co-creation of knowledge with community and university partners, deep understandings about social justice and community safety have emerged. The Circles of Safety structure, which surrounds the women with people and systems that form a safety net, addresses their needs for education, employment, family re-unification, life skills, trauma counseling, and personal goal setting as they transition from prison. In this

\footnotetext{
${ }^{1}$ I dedicate this paper to the memory of Larry Morrissette, a leader in the Indigenous community and a social justice activist who gave his life energy to his family, his children and grandchildren, his community, and the men and women who relied on his wisdom and his certainty of the goodness of all people. Larry encouraged and continues to guide this work in a good way, in its focus on social co-ops and development of prison teaching.
} 
way, the research team considers this project to be a promising response to the Truth and Reconciliation Commission's (2015) call to address the increasing rate of incarceration of Indigenous people.

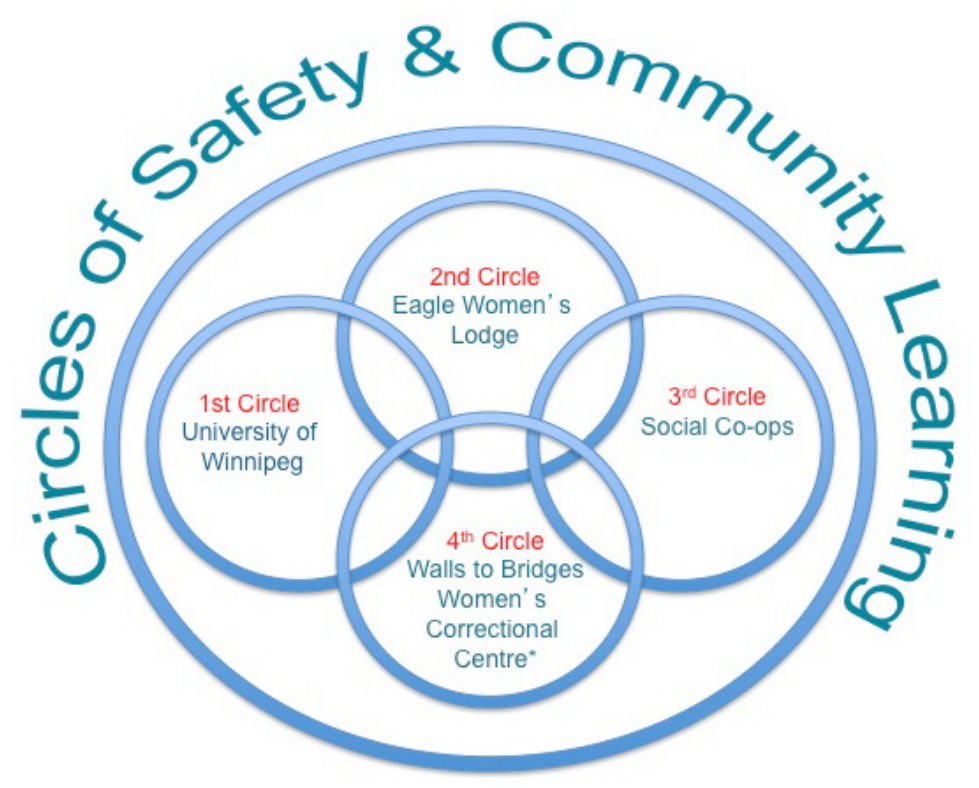

Figure 1. Circles of Safety and Community Learning (Harris \& Cyr, 2013)

Our Circles of Safety structure includes four interconnected circles or spheres of activity: the university, the community, social co-operatives, and corrections. Our strategy is to connect the University of Winnipeg (faculty, staff, students, and researchers) to Eagle Women's Lodge (an inner-city transition centre for criminalized women), the Social Cooperative Movement (based on Italian prison-based co-op models), ${ }^{2}$ and the Women's Correctional Centre (a facility for provincially sentenced women located in Headingley, Manitoba). ${ }^{3}$ In this essay, I focus on one of these circles of safety. Walls to Bridges (W2B) is a prison education program that has adapted the highly successful American Inside-Out initiative to Canada. Our classes bring campus-enrolled students to the Women's Correctional Centre to study with incarcerated students. As the project has unfolded, it has offered opportunities to explore ways in which the university can extend its mandate to address contemporary issues such as the growing numbers of Indigenous men, women, and youth populating correctional facilities. Our experience with the Walls to Bridges program contributes to the field of university-community learning practice, particularly for the many universities that find themselves working in an

\footnotetext{
${ }^{2}$ In previous research, I explore the role of social co-ops in supporting Indigenous women transitioning from prison. See McLeod Rogers and Harris (2014).

${ }^{3}$ See Figure 1 for an illustration of the Circles of Safety model. For more on this project, see Harris and McLeod Rogers (2014).
} 
inner-city environment. Both incarcerated and campus-enrolled students who participate in the program, in the unlikely setting of a secure correctional facility, benefit from this educative experience.

This article first discusses the context in which this work unfolds. It then considers what we have learned about prison education in the past four years at the Women's Correctional Centre. It examines the Walls to Bridges pedagogy in light of John Dewey's (1938) classic theory of educative experience, defined by two central principles: continuity and interaction. My reflection on the role of these principles in our prison education program highlights the potential of the Walls to Bridges approach to expand circles of safety for incarcerated students and for men and women transitioning from prison.

\section{Criminal Justice Context for University-Community Learning}

Turner and Wetzel (2014) observe that "since virtually all prisoners will return to their communities, it is better to approach their incarceration by providing conditions as close to normal as possible" (Turner \& Wetzel, 2014, para.8). Global evidence suggests that we need to reduce the numbers of people going into prison and remove them "from communities for the shortest possible time so that institutional life does not become their norm" (Turner \& Wetzel, 2014, para. 8). Anthony Doob (2014) of the Centre for Criminology, University of Toronto, argues that both the United States experience and historical evidence in Canada refute claims that a tough-on-crime agenda leads to safety and that longer sentences lead to lower recidivism rates.

Yet despite the findings drawn from these recent studies, the knowledge of those who see family members cycling in and out of prison, and the clear international examples that punishment is less effective than rehabilitation, Canada appears committed to expanding its "prison industry." Manitoba, where our project takes place, has the highest rate of incarceration in Canada at 240 per 100,000 people, almost double Canada's rate (138). The Province's occupancy rate is $127 \%$, with some jails housing five people in a cell meant for two (Reitano, 2016). Nearly one in ten prisoners in Manitoba's jail system is kept in segregation, which is believed to be the highest proportion in the country and significantly higher than the rate recorded in the federal system (Friesen \& White, 2016).

This expansion of the prison industry is justified by an "us and them" view of society that persists in dividing citizens into "deserving" and "undeserving" camps—and largely along racialized and class-based lines. Although the Indigenous population of Canada represents 4\% of the population, Indigenous people comprise $25 \%$ of those in custody and the number of Indigenous men, women, and youth in the corrections system is growing (Reitano, 2016). Of particular concern is that the fastest growing demographic in our prisons is young Indigenous women (Elizabeth Fry Society, 2014). Justice Department data indicates that the number of Indigenous women "who were locked behind bars in federal institutions grew a staggering 97 percent between 2002 and 2012" (Rennie, 2014, para. 2). Correctional Services Canada has characterized the average Indigenous woman entering federal facilities as being 27 years old with limited education (usually grade nine), unemployed or under-employed at the time of 
arrest, a sole support mother of two to three children, and a survivor of violence and abuse (as cited in Elizabeth Fry Society, 2013).

\section{The University as a Community Learning Hub}

For many years, the University of Winnipeg has seemed isolated from its neighbourhoodphysically and in terms of community relationships. Residents of the Spence neighbourhood, where the University and my own home are located, point to broken promises which have fueled resentment. David C. Perry and Wim Wiewel write: "Almost from the beginning, the relationship between the university and its surroundings has been as conflictive as it has been important_captured most commonly in the time-worn phrase 'town-gown' relations" (as cited in Toews, 2011, p. 6). In my experience, there are those within administration and among the faculty who continue to believe that scholarly activities are, and should continue to be, inaccessible to the majority and that theory and practice are separable.

Yet early on in the 1960s, the Board of Governors, faculty, and students of what was then called United College made a firm commitment to remaining in downtown Winnipeg rather than moving to the Fort Garry campus where the new University of Manitoba was established (Axworthy, 2009, p. 3). Past President Dr. Lloyd Axworthy and now Dr. Annette Trimbee (who was installed as President in July 2015) have provided leadership in integrating existing and new initiatives that reflect a commitment to opening the doors of the fortress. Axworthy (2009) defines community learning as a key theme in the future development of the university:

Community learning... describes the active integration of the university into the social, cultural and educational life of the community. It recognizes the responsibility of the university to function in an accessible manner and to open itself up to the wide diversity of knowledge and experience represented within society. (p. 1)

Not all scholarship must be community-based, but there is growing evidence of the academic quality of scholarship that values partnerships, local knowledge, and local research priorities. ${ }^{4}$ As Axworthy (2009) recounts, the aims of community learning at University of Winnipeg are to:

1) provide innovative learning opportunities for underrepresented populations;

2) use resources to analyze/address critical issues with community groups;

3) cultivate dynamic/reciprocal relationship between campus and community; and

4) understand that these are learning opportunities for our students. (p. 1)

Axworthy (2009) echoes the philosophy of the extension education movement (see

\footnotetext{
${ }^{4}$ Many examples can be found at the University of Winnipeg's Experiential Learning website: https://www.uwinnipeg.ca/ experiential learning/index.html
} 
also Dodaro \& Pluta, 2012; Sim, 1993) ${ }^{5}$ when he claims that community learning makes a difference: "The university has the immense potential to be a hub" and "use its mandate and independence" to advance "human rights and community goals" (p. 18-19). Both university and community have benefitted in terms of research, literacy, and advancing social justice work. Our work with women transitioning from prisons is one of a number of initiatives where faculty and students have engaged with community-based organizations and the community has responded in kind.

\section{The Walls to Bridges Prison Education Program}

As stated above, our prison education program is located at the Women's Correctional Centre in Headingley, Manitoba. We have taught three courses on community development and coops (L. Morrissette, B. Cyr, M. Stevenson and J. Harris), a writing course on the theme of water (J. McLeod Rogers and J. Harris), and a fifth course on Indigenous stories (K. Venema and B. Cyr). These courses build on the pedagogy of the Inside-Out Prison Exchange program, an initiative that, as noted above, was established by Lori Pompa in Philadelphia in 1995 (Davis \& Roswell, 2013) and recently launched in Canada by Simone Davis and Shoshana Pollack under

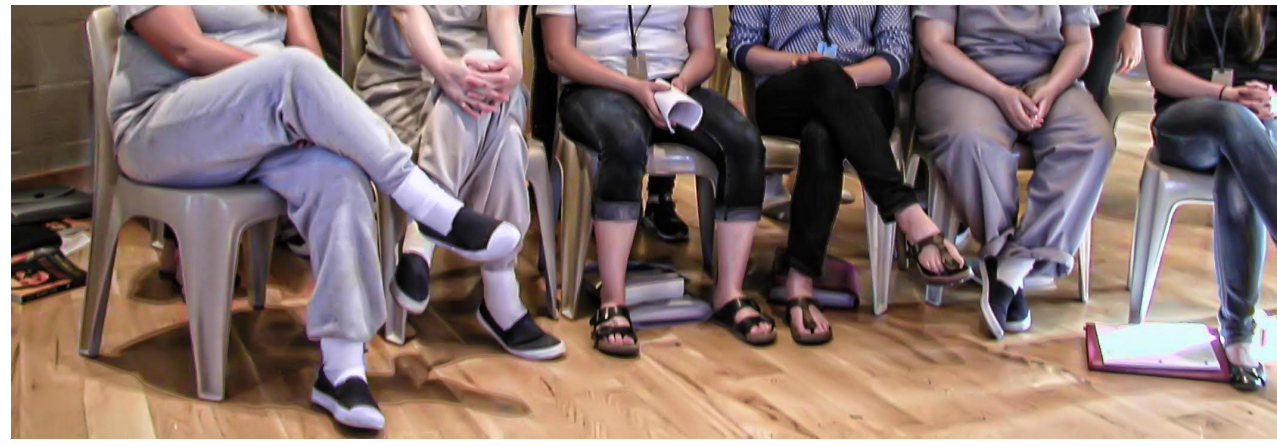

the name "Walls to Bridges." Its inspired approach is to bring incarcerated ("inside") students together with university campus-enrolled ("outside") students to take a course for credit inside the prison walls. The program emphasizes dialogue, collaboration, and experiential learning. Courses can be taught in any discipline, but the overall goal is to deepen conversation about crime, justice, freedom, inequality, and other social issues.

The impact thus far of our Walls to Bridges program is striking. The Women's Correctional Centre staff have shared with us the fact that the women inside talk with excitement about the courses and have more self-esteem as a result of participating. The "outside" students, on the other hand, have observed how surprisingly familiar the class seems, yet so different- to be sharing their thoughts face-to-face surrounded by heavy security. The classes are a place of calm reflection, yet we often suddenly find ourselves circling around raw issues like "making

\footnotetext{
${ }^{5}$ Alex Sim was one of many University of Guelph instructors whose work with rural communities through the Extension Education Department is legendary. This movement acknowledges the value of the reciprocal partnership between academia and the community. Another example is that of the Antigonish Movement (Dodaro \& Pluta, 2012).
} 
it on the street," panhandling as a moneymaking occupation, or doctors on Main Street who dispense drugs and keep the poor anesthetized.

As a result of their experience in the program, six "inside" students are taking courses and working with advisors to continue their education at the University of Winnipeg. And we expect that some of the "inside" students who completed the first course might choose to transition into the safe and supported environment of Eagle Women's Lodge (one of the connected "Circles of Safety").

\section{Walls to Bridges Pedagogy and Dewey's Theory of Experience}

Inside-Out/Walls to Bridges pedagogical values (Davis and Roswell, 2013) are rigorously integrated into teaching in courses at the Women's Correctional Centre. As noted above, between May 2014 and June 2017, our Walls to Bridges faculty have held five classes, with a total of 70 students studying together for credit towards their degrees. The Inside-Out/Walls to Bridges pedagogy employs methods that have created a "shared liminal space" — a space where we satisfy our hunger to "express our true selves beyond the expectations (external and internal) that so often imprison us" (Pompa, 2013, p. 24). These methods, as I explore below, intersect with and echo Dewey's classic theory of educative experience as informed by "continuous learning" and "multivalent interactions" (Mayer, 2015, p. 43, 45).

\section{Walls to Bridges pedagogical values}

Below I provide a skeleton of the Walls to Bridges pedagogy (based on the Inside-Out pedagogy) and refer the reader to Davis and Roswell's publication, Turning Teaching Inside Out (2013), for a more comprehensive presentation of an approach that has been refined over more than a decade by close to 500 instructors. ${ }^{6}$ Fundamental aspects of the pedagogy include the following:

- Establishing the Circle of Trust: emphasizes the difference between instrumental speech (convincing others of our rightness) and expressive speech (speaking from one's centre to the centre of the circle).

- Trusting the Process: requires instructor and students, when hearing emotional stories, to resist problem solving in response to discomfort and to expect that what unfolds in the classroom cannot always be known in advance.

- Creating Safety \& Creating Choices: happens by providing a space where students can choose what enters the conversation and instructors can model courageous discussions, recognizing when a student is trying to name a dynamic aloud and giving her/him space to do so.

- Getting There Together: entails recognizing that we can learn in collaboration and we can explore together instead of failing to listen.

- The Bass Player, Not the Rock Star: is modeled by the instructor who balances compassionate open-mindedness with courage to respond to comments that arise out of power, privilege, and oppression.

- Attending to the Force that Ambivalence Exerts: necessitates working effectively with negative affect and resistance as integral and not subversive to positive intergroup interactions, as well

\footnotetext{
${ }^{6}$ For a student perspective on the impact of these values in the classroom, see Sferrazza (this issue).
} 
as modeling honest, compassionate naming of what we see as needed.

- Instructor Awareness: requires self-reflexivity and an ability to be transparent, bringing out issues that students are seeing and addressing them in the moment — creating an opportunity for discussion.

- Learning with our Whole Selves - Emotional, Mental, Physical and Spiritual: requires deliberate dialogue and deep listening, through which students engage in a process of coming to know themselves and others.

Inside-Out founder Lori Pompa (2013) distinguishes service-learning from "the pedagogy of community-based learning [which] when done with great care and integrity, has the power to turn things inside-out and upside-down for [all] those engaged in it. It provokes one to think differently about the world, and consider one's relationship to the world in a new way" (p. 25). Rather than inhabiting the contested binary of server/served that is common to CSL, both "outside" and "inside" participants in the Inside-Out/Walls to Bridges classroom are engaged as students in a common learning project. ${ }^{8}$ The American Inside-Out Prison Exchange Program and the Canadian Walls to Bridges Program demonstrate the power of experiential education that integrates Dewey's principles of continuity and interaction. Both "inside" and "outside" students build on their existing knowledge and invest their evolving understanding in the circle of discussion (a place of profound interaction), focusing their common interest on a point in the discussion where "content meets context" (Pompa 2013, p. 16).

Simone Davis emphasizes that Canada's Walls to Bridges must evolve slowly into a program that reflects national and regional contexts (2013, pp. 257-65). Given that the American program may in its development have been influenced by the "exceptional conditions it attempts to ameliorate," having an incarceration rate many times higher than that of Canada, W2B instructors must be attentive to the challenges that present themselves as the initiative reveals itself in place. The fastest growing population in Canada's prisons is that of Indigenous men and women and families who have had intergenerational experience with corrections. Indigenous educators and students in our Think Tank (a collective of individuals who are currently incarcerated or recently released and who advise and guide the program), alongside Aboriginal Student Services, provide guidance in shaping our approach to prison education and in facilitating the students' continuing education at post-secondary institutions.

\section{Taking Dewey's theory of experience into the prison}

In referring to "community service-learning" or to "experiential learning," one runs the risk of suggesting that these approaches are undertaken independently of more "traditional learning." But Dewey (1938), who is often referred to as the father of the experiential education movement, describes an organic relationship (p. 74) between the traditional and the progressive forms of education emerging in the 1930s. His is a theory of experience that complements theories of education in the traditional classroom. Drawing on Dewey, I define "experiential learning" as learning in situations that begin with the experience that the learners

\footnotetext{
${ }^{7}$ See Aujla and Hamm, this issue.

${ }^{8}$ See Davis, this issue, for more on the distinction between Walls to Bridges and CSL.
} 
already have and subject matter that is within the scope of their ordinary life-experience, leading to their formation of purpose. The instructor might cultivate such learning by taking students out of the classroom to observe work that addresses an issue of concern, and then encouraging them to analyze the connections between what they have learned in the past and what they are currently observing. Another experiential learning situation could be arranged by bringing together two groups of people who have had distinctly different life paths. Again, the memories and analyses that students present in discussion can generate individual and group learning and conclusions. Each of these educative situations is characterized by interaction that sparks a response. Experience involves exposure to new physical situations and, in the second case, exposure to new ideas as different worlds converge. The University of Winnipeg's Walls to Bridges program in fact combines both experiential learning situations.

According to Dewey (1938), the two foundational principles of an educative experience are continuity of experience and interaction of internal and external factors. He comments on four key elements of this philosophy of education: freedom, formation of purpose, subjectmatter, and the role of the instructor. As Mayer (2015) summarizes, "Dewey believed that what he called continuous learning must be directed in part by the learner-in accordance with the learner's present confusions, capacities, and understandings-while also being organized by intellectually challenging interactions with a teacher, peers, and pedagogically generative artifacts and phenomena" (p. 43, emphases mine). In other words, education is not a static endeavour, where learning "means acquisition of what already is incorporated in books" (Dewey, 1938, p. 19) and instructors provide content isolated from the context of its reception. Rather, educators have a responsibility to understand "the needs and capacities of the individuals who are learning at a given time" (Dewey, 1938, p. 46) and to connect the subject matter of the class with relevant individual and social contexts. In the case of our program, with its two ("inside" and "outside") student groups and the unusual, liminal space created inside a correctional facility, Dewey's theory of experience helps illuminate the ways in which Walls to Bridges provides a continuous and interactive learning experience, where knowledge is located in the present experience of those in the room, but "stretched," as Dewey says, to take into account both the past and the future: "[Present experience] can expand into the future only as it is also enlarged to take in the past" (p. 77).

\section{Continuity and Interaction: From Incarceration to Post-Secondary Education}

Dewey's (1938) discussion of the first principle, continuity, directs both educators and students to draw from accumulated experience and apply this knowledge to alter future experience: "[T] he principle of the continuity of experience means that every experience both takes up something from those which have gone before and modifies in some way the quality of those which come after" (p. 35). Experience, he explains, "if it arouses curiosity, strengthens initiative and sets up desires and purposes, will carry a person over dead places in the future" (p. 38). The "dead spaces" that we all face, but that might especially follow one released from prison into an unsupportive community, are a central concern in the Walls to Bridges program. Prison education represents hope and a path into the future to carry one over a 
period of difficult transition. As Dewey (1938) explains, "The principle of continuity in its educational application means...that the future has to be taken into account at every stage of the educational process" (p. 47).

Before beginning a Walls to Bridges class, outside students are screened by instructors. The process is intended both to orient them to studying in the prison and to ensure that they are not simply adopting a "service" or charity-based mentality—all are co-learners. Students who do not support the right of those in prison to education are not approved for the class. For all students, it is an opportunity to have a conversation with the instructor, who can then begin to understand how to connect with their individual experiences. Neill (2005) expands on the importance of continuity in relation to the existing experience of students: "Once we have a theory of experience, then as educators, we can set about progressively organizing our subject matter in a way that takes account of a student's past experience and then provides them with experiences which will help to open-up rather than shut down [their] access to future growth experiences, thereby expanding [their] likely contribution to society" (para. 11). If we as instructors do not know the "powers and purposes" of those we are teaching, then the process of teaching and learning becomes "accidental" (Dewey, 1938, p. 45). But as prison educators, we are teaching adult students, and it is impossible to know everyone's full story. With incarcerated students in particular, we need to be respectful of boundaries; it is up to each person to share his or her experiences if they wish. Two questions arise: "How much do we need to know about a student's background in order to ensure that there is continuity in the educational experience?" and "Are there exercises that will assist the instructor in understanding how to make connections to the student's past experience?"

Our approach in Winnipeg has been to work closely with the teacher at the Women's Correctional Centre in selecting the inside students who we enroll in our classes. We are aware however that the correctional environment in North America is generally one of "reward and punish," and there is therefore a danger that our program could be coopted by that system if, for example, a students' ability to enroll or participate in classes is linked to "good" or "bad" behavior or past crimes, as adjudicated by the system. As we continue to establish administrative procedures through negotiation with the correctional institution, we aim to collaborate on a screening process for the inside students as a means of maintaining a degree of independence. With each institution we are dependent on a stable working relationship that must steer a course above a sea of regulations and attitudes that can change unexpectedly and could scuttle the program. It is clear that by bringing a university group inside to enter into a dialogue with prisoners, Walls-to-Bridges is starting to pull away a veil that prevents society from understanding the corrections system.

Walls-to-Bridges in Manitoba has access to advisors who are well-informed and understand how the prison population represents those whose lives have been lived at the intersection of 
race, poverty and gender. ${ }^{9}$ University of Winnipeg's Aboriginal Students Services staff has been going into the prisons for many years. They work very closely with formerly incarcerated students who they meet with before their release and for the duration of their studies. Our Manitoba Think Tank of alumni and educators advises us on how to evaluate our impact on the students serving time. Inside-Out and Walls-to-Bridges Think Tanks across the USA and Canada are sites of debate, research, and action, often advocating for needed change in prison conditions.

The students in our classes make meaningful connections with each other, sharing their past and present experiences and thus creating an environment conducive to Dewey's notion of continuous learning. I have observed that the students show concern for each other and appreciation for each other's knowledge. They are curious about the "other's" life experiencethe university experience on the one hand and what has led to incarceration on the other. They suspend judgment about privilege and about involvement in illegal activity as they work together on group projects_-for example, designing new workers' co-operatives in classes on community development and co-operatives. Pollack (2016), too, highlights the relational and intellectual impacts of Walls to Bridges pedagogy on students and describes the dismantling of labels (p. 7). A recent graduation presentation by one of the "inside" students expresses this in vivid terms: "The opportunity took our moments of grey and gave us colours of hope" (Walls to Bridges Manitoba participant, personal communication, June 28, 2016).

There is a clear change for both groups of students in how they see themselves, given the chance to engage in collaborative learning. Student evaluations have identified circle pedagogy as an effective method for connecting one's centre to the centre of the circle (Palmer 2009, p. 119). Both groups experience change as personal development that arises from "talking to ourselves," that is, our inner teacher (Palmer, 2009, p. 121). Palmer and Little Bear (2000) are standard readings in the first week of W2B classes. Both educators speak of the transformational effect of learning through experience (Little Bear, 2009, p. 81) and both reject interference and the practice of setting each other straight. By speaking our truth to the circle and listening to our inner teacher or authentic self, we are able to carry our understanding with us when we leave the class, reflecting Dewey's (1938) concept that "[e]ducation as growth or maturity should be an ever-present process" (p. 50).

Continuity behind the prison walls can also take the form of continued studies. As Dewey (1938) observes, "[t]he most important attitude that can be formed [through an educative experience] is that of the desire to go on learning" (p. 48). Walls to Bridges pedagogy cultivates this desire in participants. On the one hand, the "outside" students have shown a continuing interest in learning more about corrections and have asked to be involved in follow-up initiatives, indicating a commitment that has grown out of their discussions with

\footnotetext{
${ }^{9}$ The University of Winnipeg, in line with its strategic direction on Indigenization, now requires all students to meet the Indigenous Course Requirement (ICR). The office of the VP Indigenous Affairs provides supports for faculty integrating Indigenous content and pedagogy into their courses. The University is committed to best practices in teaching that recognizes race, class, and gender issues. The University's Urban and Inner-City Studies in Winnipeg's north end (the author has taught in this department since 2007) is attracting many students who face barriers of racism, and classism.
} 
"inside" students. For "inside" students, W2B classes importantly, and at a minimum, meet fundamental needs related to self-esteem, cognition, and self-actualization. Inside students are clearly hungry for learning but continuing education can be more difficult and hard to access. Provincially sentenced women, like our students at the Women's Correctional Centre (who serve sentences of up to two years less a day), are not provided with the same degree of programming (educational and otherwise) that is available to federally sentenced women, who face longer periods of incarceration. For these students, we will negotiate involvement in an inside Think Tank.

Support for students interested in post-secondary education once they are released is also an important part of the Walls to Bridges program. Our University of Winnipeg admissions, student advising, and Aboriginal Student Services Centre staff are well aware of the challenges faced by students as they transition into the community and enroll in more courses. Our Think Tank has the intention of offering a clear path and smooth transition, and together with Students Services will provide an integrated education plan for the "inside" students. Of course, keeping in touch with students once they are released is a challenge and a source of concern, given the factors that contribute to the revolving door that is the penal system. One recommendation made at a recent debriefing that involved Women's Correctional Centre staff and University of Winnipeg staff and faculty members called for the program to offer the continuing education course "Intro to University" in advance of Walls to Bridges courses so that the "inside" students are well-prepared for classes and have a solid foundation for continuing study. Tutors are included in the program at the prison and meet weekly with the students to help them with readings and assignments.

"Interaction" is the second key principle in Dewey's (1938) theory of educative experience. The development of experience, he explains, comes through interaction: internal and external; longitudinal and lateral; instructor and student; student to student; and for past, present, and future understandings (p. 42). In the Walls to Bridges classroom, the standard use of interactive exercises and ice breakers in the first three to four classes can function in a practical way not only to build relationships, as Pollack (2016) recommends (p. 11), but also to identify learning styles, personal goals, and ideologies so that subject matter is more likely to match with the students' purposes in taking the class and their academic goals.

Walls to Bridges circle pedagogy is oriented towards maximum interaction. Dewey (1938) observed that "every experience is a moving force" (p. 38). In Walls to Bridges classes, instructors commonly use conversation circles and "wagon wheel" exercises, where an inner circle of "outside" participants sits facing an outer circle of "inside" participants. The inner circle remains stationary while the outer circle rotates as students share responses to facilitators' questions. Such encounters focus our attention-we are "listening hard" (S. Davis, personal communication, April 5, 2015) and interacting deeply. With its connection to Indigenous epistemologies, circle pedagogy is particularly resonant in our Walls to Bridges classes, which take place on Treaty 1 Territory with Indigenous and non-Indigenous students. According to Métis author Graveline (1996), in circle pedagogy "one person speaks at a time; the person holding the special object is the speaker; and all others are to be respectfully listening to that 
person" (p. 179). "[Y] ou speak your own voice," she continues, "describe what your own experience has been," and "speak from your heart" (p. 179). Beck and Walters (as cited in Graveline, 1996) characterize the circle process as "collective mindfulness" (p. 178). Graveline further speaks of the "energy of a circle" that creates a space "to allow for the unorthodox to enter and the unexpected to happen" (p. 180). Those who have experience with Indigenous circle pedagogy are aware that as each person in turn responds to the collective understanding that is encompassed by the ring of participants, energy also accumulates and makes its way around-borne by a talking stick or stone. I have personally felt the heat of the stone as it is infused with the expanding illumination on the issues at hand and the deepening emotions of the group.

In the circle, relations among students and between students and instructor are equalized and generate a feeling of trust-something that is often lacking in academic discussion and a barrier to full exploration of difficult and critical issues. Dewey (1938) observed that it is often the "collateral learning in the way of formation of enduring attitudes" (p. 48) that is most important to educative experience, rather than the subject matter per se. Classes that prioritize interaction, create trust, and focus on social justice issues present an opportunity for students to consider the structural causes of conflict in relation to their own experiences. In this context, "inside" students come to realize that an environment of violence and social exclusion in some part has likely predetermined their path into prison (Hannah-Moffat \& Shaw, 2000, p. 15). Reflection on these realities may help them to distinguish those past events which came under their control from those that were the consequence of wider forces. Through this collateral learning, students can sometimes come to terms with the present and plan for the future.

\section{Reflections on Experiential Learning in Walls to Bridges and Circles of Safety}

In this essay, I have focused on a university-community initiative to address the vulnerability of justice-involved women. Circles of Safety can be understood as a social justice strategy and a framework for collaboration within and among institutions based on the prioritization of safety above (although not exclusive of) poverty-alleviation and risk-assessment, fostering socio-economic inclusion and protecting our communities. A safety lens allows us to see each other, listen to each other, engage with each other across differences in race, income, and gender identity, and to create alliances across the boundaries that separate us. The university and its inner-city neighbours are creating alliances based on a mutual respect for the knowledge that we each can bring to the table and to the classroom. Together, we may have the capacity to confront the very real challenges ahead. In 2018, Harris and Stevenson are introducing a course at the Stony Mountain Institute, a facility that houses maximum, medium, and minimum security men. We are aware that we must be attentive and draw on our previous experience in order to put in place measures to create a safe place for men and women in the class.

Among those who bear the costs of racial and class rifts in our fragmented society are the growing numbers of Indigenous women populating our prisons. For crimes of poverty, they are often provincially sentenced in facilities that have fewer options for programming.

Engaged Scholar Journal: Community-Engaged Research, Teaching and Learning 
Hannah-Moffat and Shaw (2000) analyze the paths that men and women take into prison and remind us that "the context in which behaviour takes place needs to be considered, in terms not only of the immediate actors, but also of preceding experiences and events" ( $\mathrm{p}$. 15). For women in particular, these experiences and events include prostitution; drug use (not trafficking); theft of clothing, groceries, and make-up; and welfare fraud. These are the activities women are drawn into upon release. Wrap-around services and circles of safety must surround the women and introduce them to paths that lead to more hopeful futures.

The Walls to Bridges program in Canada and its parent, the Inside Out program, have established an approach that demonstrates the continuing relevance of Dewey's classic theory of experience, and Dewey, in turn, sheds light on the value and transformative capacity of these programs. Eight W2B pedagogical values (Davis \& Roswell, 2013) are set in motion in the Walls to Bridges class we are conducting at the Women's Correctional Centre: an understanding of structural factors that influence our lives; a co-learning process that empowers the students to create an internal order to the subject matter; the formation of a circle of trust that encourages students to draw on their whole selves; the development of interpersonal and analytical skills that can be applied to conditions that will arise in the future; instruction focused on the present and on honest and compassionate naming of what we see; and expanding awareness of historical knowledge that brings awareness of a changing world.

Dewey's principles of continuity and interaction are integrated emotionally, physically, mentally, and spiritually in the circle of trust that provides the physical setting for classes. Walls to Bridges honours what students bring to the circle from their experience. The circle is a safe environment and one that leaves room, as Dewey (1938) would urge, for the necessary free play of individual thinking (p. 58). To learn in such a space is something for which we all hunger, but incarcerated women are starved for such an experience, which can explain their past, respect them as individuals, and engage them in purposeful discussion. Our intention is that their education inside and outside of prison and the connections and relationships built along the way might help to carry them safely over some of the difficulties of transitioning into the community.

\section{Acknowledgements}

I acknowledge our research team over the past four years, which has included J. McLeod Rogers (Rhetoric, Writing and Communication) and K.Venema (English) from University of Winnipeg; M. Stevenson from the Millennium Centre; B. Cyr, formerly ED of Native Women's Transition Centre; and L. Morrissette from Ogijiita Pimatiswin Kinamatwin. Many others have supported the Walls to Bridges program in significant ways. We have also established a working group of faculty at University of Winnipeg and a Think Tank (similar to those in the USA and Canada) of instructors and former inside and outside students. 


\section{About the Author}

Judith Harris is an Associate Professor in Urban and Inner-City Studies, University of Winnipeg and a member of Manitoba's Walls to Bridges group. Her on-going interest is in defining the Economy of Safety for inner-city women and for universal application. Email: j.harris@uwinnipeg.ca

\section{References}

Axworthy, L. (Fall 2009). The university and community learning: An evolving mission.

Davis, S., \& Roswell, B. (Eds.). (2013). Turning teaching Inside Out: A pedagogy of transformation for community-based education. New York, NY: Palgrave MacMillan.

Dewey, J. (1938). Experience and education. New York, NY: Macmillan.

Dodaro, S., \& Pluta, L. 2012 The Big Picture: The Antigonish Movement of Eastern Nova Scotia. Montreal, QC: McGill-Queens.

Doob, A. N. (2014, May 9). Toward creating an informed electorate: Understanding criminal justice policy. Presentation at Educating Justice: Postsecondary Education in the Justice Disciplines, a Centre for Interdisciplinary Justice Studies conference, University of Winnipeg, Winnipeg, $\mathrm{MB}$.

Elizabeth Fry Society. (2013). Indigenous women.

Elizabeth Fry Society. (2014). Human and fiscal costs of prison.

Friesen, J., \& White, P. (June 9, 2016). Solitary confinement used most in Manitoba jails. Globe and Mail.

Graveline, M. J. (1996). Circle as pedagogy: Aboriginal tradition enacted in a university classroom. (Unpublished thesis). Dalhousie University, Halifax, Nova Scotia.

Hannah-Moffat, K., \& Shaw, M. (2000). Gender, diversity and risk assessment in Canadian corrections. Probation Journal, 47(3), 163-172.

Harris, J., \& McLeod Rogers, J. (Fall 2014). Complex alliances: A community- and institution-based project for educating justice-involved women. Annual Review of Interdisciplinary Justice Research, 4, 211-233.

Little Bear, L. (2000) Jagged worlds collide. In M. Battiste (Ed.), Reclaiming Indigenous voices and vision (pp.77-85). Vancouver, BC: UBC Press.

Mayer, S. J. (2015). Representing Dewey's constructs of continuity and interaction within classrooms. Education and Culture 31(2), 39-53.

McLeod Rogers J., \& Harris, J. (Summer 2014). Partnering to build social co-operatives for Aboriginal women transitioning from prison. Journal of Co-operative Studies, 47(1), 25-38.

Neill, J. (2005, October 1). 500 word summary of Dewey's Experience and Education.

Palmer, P. (2009). Deep speaks to deep. In A Hidden Wholeness: The Journey Toward an Undivided Life (pp. 113-128). San Francisco, CA: Jossey-Bass.

Engaged Scholar Journal: Community-Engaged Research, Teaching and Learning 
Pompa, L. (2013). Drawing forth, finding voice, making change: Inside-out learning as transformative pedagogy. In S. Davis \& B. Roswell (Eds.), Turning teaching Inside Out: A pedagogy of transformation for community-based education (pp. 13-26). New York, NY: Palgrave MacMillan.

Reitano, J. (2016, March 22). Adult correctional statistics in Canada.

Rennie, S. (2014, December 2). Big spike in aboriginal women behind bars, study finds. CBC News.

Sapers, H. (2014). Annual Report of the Office of the Correctional Investigator, 2013-2014.

Sapers, H. (2015). Annual Report of the Office of the Correctional Investigator, 2014-2015.

Sim, R. Alex. (1993). The changing culture of rural Ontario. Occasional Papers in Rural Extension No. 9, Guelph University.

Toews, O. (August 2010). From revitalization to revaluation in the Spence neighbourbood.

Truth and Reconciliation Commission of Canada. (2015). Honouring the truth, reconciling for the future: Summary of the final report of the Truth and Reconciliation Commission of Canada.

Turner, N., \& Wetzel, J. (2014, May 22). Treating prisoners with dignity can reduce crime. The Atlantic. 